https://doi.org/10.30910/turkjans.448712

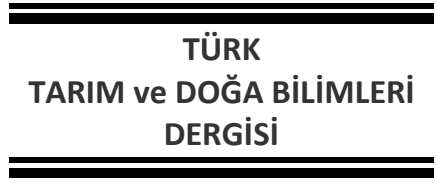

TÜRK DERGISI

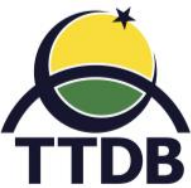

www.dergipark.gov.tr/turkjans

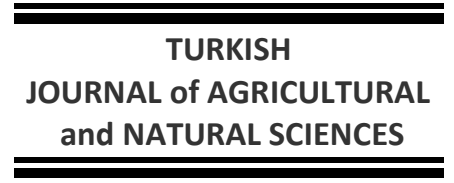

Araştırma Makalesi

\title{
Bingöl İli Merkez İlçede Kayısı Ağaçlarında Tespit Edilen Fungal Hastalık Etmenleri
}

\author{
IşII SARAÇ*
}

Bingöl Üniversitesi Ziraat Fakültesi Bitki Koruma Bölümü, Bingöl

*Sorumlu yazar: saracsaracisil@hotmail.com

Geliş Tarihi: 20.02.2018

Düzeltme Geliş Tarihi: 05.06.2018

Kabul Tarihi: 18.07.2018

\section{Özet}

Dünyada sert çekirdekli meyve yetiştiriciliği yapılan alanlarda Ceratocystis sp. (Ceratocystis kanseri), Cytospora sp. (Cytospora kanseri), Verticillium ve Fusarium solgunlukları, ciddi zarara verim düşüşlerine ve ağaç kayıplarına yol açan önemli fungal etmenlerdir. Bu çalışma ile Bingöl ili merkez ilçede 2017 yıllında kayısı ağaçlarında problem teşkil eden fungal etmenlerin saptanmasına çalışılmıştır. Çalışma sonucu, kayısı ağaçlarında Monilya (Monilinia laxa Aderhold and Ruhland) Honey), Yaprak Delen (Wilsonomyces carpophilus Adaskaveg) [Stigmina carpophila (anamorph M.B. Ellıs)] ve yaprak ve meyvelerde leke yapan Alternaria sp. tespit edilmiştir. Kayısı ağaçlarında \%74 oranında Wilsonomyces carpophilus, \%45 oranında Monilinia laxa, \%15 oranında Alternaria sp. izole edilmiştir.

Anahtar kelimeler: Kayısı, fungal hastalıklar, Wilsonomyces carpophilus, Monilinia laxa, Bingöl.

\section{Fungal Disease Factors Detected in Apricot Trees in Bingol Province}

\begin{abstract}
In the regions where stone fruits are grown in the world, Ceratocystis sp. (Ceratocystis cancer), Cytosporasp. (Cytospora cancers, backward death), Verticillium and Fusarium wilts, significant damage to hardseeded fruit trees, loss of yield and loss of trees. In this study, it was tried to determine the fungal factors in apricot trees in Bingöl province in 2017. The presence and density of fungal agents in the central region have been determined. Monilinia (Monilinia laxa Aderhold and Ruhland)Honey), Wilsonomyces carpophilus Adaskaveg (Stigmina carpophila (anamorph)) and Alternaria sp. In apricot trees, $74 \%$ of Wilsonomyces carpophilus, $45 \%$ of Monilinia laxa, $15 \%$ of Alternaria sp. It was isolated.
\end{abstract}

Key words: Apricot, fungal disease, Wilsonomyces carpophilus, Monilinia laxa, Bingol.

Giriş

Ülkemizde kayısı yetiştiriciliğinden yılda 1238052 ton ürün elde edilmektedir. Bingöl ili ise, bu üretime 255 ton ile katkıda bulunmaktadır (TÜik, 2016). Dünyada sert çekirdekli meyve üretimi yapılan alanlarda, Ceratocystis sp. (Ceratocystis kanseri), Cytospora sp. (Cytospora kanseri), Verticillium ve Fusarium solgunlukları, sert çekirdekli meyve ağaçlarında ciddi hasarlara, verim düşüşlerine ve ağaç kayıplarına yol açan önemli fungal etmenlerdir (Ogawa ve ark. 1995).

Türkiye'de sert çekirdekli meyve ağaçlarında zarar oluşturan fungal patojenlerin tespiti ile ilgili olarak yapılan çalışmalar yoğun değildir. Elazığ, Malatya, Tunceli, Erzincan ve Kahramanmaraş, illerinde yürütülmüş bir çalışmada, kayısı bitkisi de dahil olmak üzere bazı Rosaceae familyasına ait bitkilerde hastalık oluşumuna sebep olan Gymnosporangium (memeli pas)' a ait bazı türlere rastlanmıştır (Dinç ve Yılmaz, 1978).

Malatya ve Elazığ illerinde kayısı üretilen bölgelerde yürütülen çalışmalarda yaygın olarak Cytospora sp., Monilia laxa (çiçek monilyası), Wilsonomyces carpophilus (Yaprakdelen ve 
meyvede çil hastalığı) tespit edilmiştir (Kural ve Erdiler, 1995; Özgönen ve Erkılıç, 2001).

Günümüzde, sert çekirdekli meyve yetiştiriciliği yapılan alanlarda çiçeklenme periyodunda monilya ve çiçeklenme periyodu sonrasında çil hastalıkları ile mücadele edilmeden yetiştiricilik mümkün olamamaktadır. Ayrıca, ağaç kayıplarına sebep olan fungal hastalık etmenleri önemli ekonomik kayıplar oluşturmaktadır. Bingöl'de, hastalık ve zararlılarla gerekli düzeyde mücadele edilmemesinden ve yeterli kültürel önlemlerin alınamamasından dolayı ağaç kayıpları yaşanmaktadır. Bu sebeple, bölge çiftçisi kayısı yetiştiriciliğinden beklediği verimi alamamaktadır. Kayısı üretiminden elde edilen kazancın, günümüz şartlarına göre masrafları bile karşılamayacak şekilde olması, kayısı ağaçlarına gösterilen ilginin azalmasına sebep olmaktadır. II genelinde dikim şartlarına uygun şekilde yetiştirilmeyen fidanlar, kurumalara neden olmakta, bölge dışından getirilen sertifikasız fidanlar ise beraberinde birtakım hastalıkları getirmektedir. Bu hastalıklar enfekte ettikleri ağaçları kısa sürede öldürmekte ve hatalı yetiştiricilik uygulamaları sebebiyle, hastalıkların süratli bir şekilde yayılmasına neden olmaktadır.

Yürütülen bu çalışma ile Bingöl ìli merkez ilçede yetiştirilen kayısılarda mevcut fungal hastalık etmenleri, bulunma oranları, yoğunlukları ve bu etmenlere karşı gerekli önemlerin belirlenmesi amaçlanmıştır.
Bölgede kayısı ağaçlarında yapılan sürveylerde yapraklarda saçma deliği şeklinde semptomlar, meyvelerde lekeler, dal ve sürgünlerde lezyonlar, sararma belirtileri, solgunluk belirtileri, gövde veya dallar üzerindeki nekrotik ve kanser gibi simptomlar dikkate alınarak, ağaç sayısı 50-100 olan bahçelerden 10 ağaç, 100-200 olan bahçelerden 20 ağaçta örnekleme yapılmıştır. Fungusların izolasyonu için yapılan surveyler sırasında hastalıklı olduğundan şüphelenilen ağaçlardan meyve, yaprak, ince dal ve sürgünlerden örnekler alınmıştır. Alınan örnekler etiketlendikten sonra kese kâğıtlarında muhafaza edilerek laboratuvara getirilmiş ve izolasyonları yapılmıştır. Hastalıklı kısımlardan parçalar alınıp \%2'lik $\mathrm{NaOCl}$ de bekletilerek yüzeysel sterilizasyonları yapılmıştır. Steril edilen parçalar PDA (Potato Dextrose Agar) ortamında kültüre alınıp, her örnekten dörder petri hazırlanmıştır. PDA ortamı içeren petriler $25 \pm 2^{\circ} \mathrm{C}^{\prime}$ de 7 gün inkübe edilmiştir. Gelişen misellerden fungal etmenler tespit edilmeye çalışılmıştır. Çalışma 2017 yılı Nisan, Mayıs ve Haziran aylarında toplanan örneklerle Bingöl Üniversitesi Ziraat Fakültesi Bitki Koruma Bölümü Fitopatoloji laboratuvarında yapılmıştır.

\section{Bulgular ve Tartışma}

Hastalıklı bitki parçalarından yapılan izolasyonlarda bulunan fungal etmenler Çizelge 1'de verilmiştir.

\section{Materyal ve Yöntem}

Çizelge 1. Kayısı ağaçlarından 2017 tarihlerinde yapılan örneklemede izole edilen fungus türleri, isolasyon alanları ve oranları.

\begin{tabular}{llc}
\hline Hastalık etmeni & İolasyon yapılan alan & Etmen izolasyon oranı (\%) \\
\hline Monilia laxa & Kabuk alt bölgeleri (Sürgün ve ya ince dallar) & 45 \\
Alternaria spp. & Yaprak & 15 \\
Wilsonomyces carpophilus & İnce dal, sürgün, yaprak & 74 \\
\hline
\end{tabular}

Arazi çalışmaları esnasında kayısı ağaçlarında görülen Alternaria $s p$. ve $M$. laxa' nın şiddetli belirtilere ve zarara yol açmadığı ve izolasyonu sağlanan fungal etmenlerin meyve ağaçlarında lokal belirti oluşturdukları tespit edilmiştir. Ancak, bölgede kayısı ağaçlarında tespit edilen ve Yaprak Delen (çil) Hastalığına neden olan W.carpophilus, yapraklarda yırtılmalara, meyvede çil lekelerine ve yapraklarda infeksiyonlara neden (ne tür enfeksiyon) olduğu tespit edilmiştir.

Yapılan çalışmada yaprakdelen, $W$. carpophilus'un bölgede en yoğun etmen olduğu, fungusun tüm örnekleme alanlarında bulunduğu ve ekonomik anlamda zarar yaptığı tespit edilmiştir (Çizelge 1).. Bununla birlikte örnek alınan alanların hemen hemen hepsinde değişik yoğunluklarda $M$. laxa izole edilmiştir. Özgönen ve Erkılıç (2001) tarafından Malatya ve Elazığ illerinde kayısılarda görülen hastalıkların ve yaygınlıklarının belirlenmesine yönelik yapılan çalışmada da yaygın şekilde Cytospora sp., Monilia laxa, Wilsonomyces carpophilus ve yaygın olmayan şekilde ise Chondrostereum purpureum izole edilmiştir. Malatya ve Elazığ illerinde kapama bahçelerin yaygınlığı ve monokültür yetiştiricilik yapılması belirtilen hastalıkların yoğunluğunun artmasına ve ekonomik ölçüde zarar oluşturmasına sebep olmaktadır Dünyada kayısı yetiştiriciliği yapılan bazı alanlardaki enfeksiyon oranları; İtalya'nın Puglia bölgesinde \%35.9 (Di Terlizzi ve ark., 1992), İspanyanın Murcia bölgesinde \%30 (Dominiquez ve ark., 1998) farklılık göstermektedir. Tespit edilen ortalama enfeksiyon oranı, Malatya, Elazığ ve Iğdır illerinde yapılan çalışmalara (Sipahioğlu ve ark.,1999; Sipahioğlu ve Baloğlu, 2001) oranla çok daha düşüktür. Bingöl' de kayısı yetiştiriciliğinin 
daha çok küçük çapta aile yetiştiriciliği şeklinde yapılması hastalıkların yayılmasını önemli derecede sınırlandırmaktadır.

\section{Sonuç ve Öneriler}

$\mathrm{Bu}$ çalışmayla birlikte, fungal etmenlerin Bingöl'de yetiştirilen kayısı ağaçlarının bir kısmında üretimi sekteye uğratacak şekilde kayıplara sebep olduğu belirlenmiştir. Bu durumun genellikle üreticilerin aile yetiştiriciliğini benimsemesinden, bu hastalıkların yeterince tanımamasından ve gerekli mücadelenin zamanında yapılmamasından kaynaklandığı düşünülmektedir..Bununla birlikte W.carpophilus'un sebep olduğu Yaprak Delen ya da Çil Hastalı̆ıı'nın bölge kayısılarında ciddi tahribata neden olması dikkat edilmesi gereken bir husustur. Fungusun bölgede daha yaygın hale gelmesi kayısı yetiştiriciliğinde verim kaybına sebep olacaktır. Bu nedenle, üreticilerin hastalıktan ari sertifikalı fidan tercih etmeleri, dayanıklı çeşit kullanmaları, kültürel önlemler ve diğer mücadele yöntemlerine önem vermeleri fungal hastalıkları önlemede büyük katkı sağlayacaktır.

\section{Kaynaklar}

Dinç, N., Yılmaz, M.A. 1978. Investigation on Gymnosporangium spp. in eastern and southern areas of Turkey. J.Turkish Phytopath., 7(2-3): 99-104.

Di Terlizzi, B., Murolo, O. Savino, V., Digiaro, M. 1992. Viruses of peach, plum and apricot in Apulia. Acta Horticulturae, 309: 367-372.

Dominiquez, S., Aparicio, F., Sanchez-Navarro, J.A., Pallas, V., Cano, A., Garcia-Brunton, J. 1998. Studies on the incidence of ilarviruses and apple chlorotic leaf spot virus (ACLSV) in apricot trees in the Murcia region (Spain) using serological and molecular hybridisation methods. Acta Horticulurae, 472(2): 203-207.

Kural, I.., Erdiler, G. 1995. Cytospora cancer of apricot in Malatya and Elazığ province. Acta Horticulturae, 384: 533-536.

Ogawa, J.M., Zehr, E.I., Ritchie, G.W., Urio, K., Uyemeto, J.K. 1995. Compendium of Stone Fruit Disease. APS Press, USA

Özgönen, H., Erkılıç, A. 2001. Malatya-Elazı̆̆ yöresinde kayısılarda görülen fungal hastalıkların ve yaygınlık oranlarının belirlenmesi. Türkiye IX. Fitopatoloji Kongresi (3-8 Eylül, 2001, Tekirdağ) Bildiriler, s. 669-675.

Sipahioğlu, H.M., Myrta, A., Abou-Ghanem, N., Di Terlizzi, B., Savino, V. 1999. Sanitary status of stone fruit trees in East Anatolia (Turkey) with particular reference to apricot. Bulletin OEPP/EPPO Bulletin, 29: 439-442.
Sipahioğlu H.M., Baloğlu, S. 2001. The incidence of prunus necrotic ringspot (PNRSV) and apple chlorotic leafspot (ACLSV) viruses on stone fruits grown in east Anatolia of Turkey, XIIth International Symposium on Apricot Culture and Decline 10th September 2001 Avignon, France.

TÜiK, 2016. http://www.tuik.gov.tr. 